Jul 12th, 8:30 AM - 8:50 AM

\title{
Development of a novel mobile industrial-scale fluidized adsorption process for emergency treatment of water polluted by aniline: CFD simulation and experiments
}

Zhaolin Du

Harbin Institute of Technology, carlcarl1988@163.com

Tong Zheng

Harbin Institute of Technology, zhengtong@hit.edu.cn

Huizhe Cao

Harbin Institute of Technology, 664708558@qq.com

Jiping Jiang

Harbin Institute of Technology, jiangjp@sustc.edu.cn

Peng Wang

Harbin Institute of Technology, State Key Laboratory of Urban Water Resource and Environment,

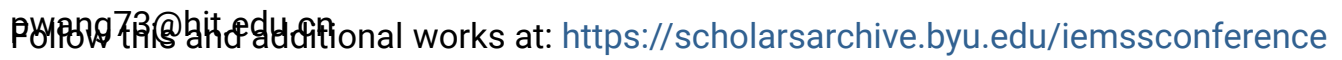

Part of the Civil Engineering Commons, Data Storage Systems Commons, Environmental Engineering Commons, Hydraulic Engineering Commons, and the Other Civil and Environmental Engineering Commons

Du, Zhaolin; Zheng, Tong; Cao, Huizhe; Jiang, Jiping; and Wang, Peng, "Development of a novel mobile industrial-scale fluidized adsorption process for emergency treatment of water polluted by aniline: CFD simulation and experiments" (2016). International Congress on Environmental Modelling and Software. 60.

https://scholarsarchive.byu.edu/iemssconference/2016/Stream-A/60

This Event is brought to you for free and open access by the Civil and Environmental Engineering at BYU ScholarsArchive. It has been accepted for inclusion in International Congress on Environmental Modelling and Software by an authorized administrator of BYU ScholarsArchive. For more information, please contact scholarsarchive@byu.edu, ellen_amatangelo@byu.edu. 


\title{
Development of a novel mobile industrial-scale fluidized adsorption process for emergency treatment of water polluted by aniline: CFD simulation and experiments
}

\author{
Zhaolin DU ${ }^{\text {a }}$, Tong ZHENG ${ }^{\mathrm{a}^{*}}$, Huizhe CAO ${ }^{\mathrm{a}}$, Jiping Jiang ${ }^{\mathrm{a}}$, Peng WANG ${ }^{\mathrm{a}, \mathrm{b}^{*}}$ \\ a. School of Municipal and Environmental Engineering, Harbin Institute of Technology, Harbin 150090, \\ China;(carlcarl1988@163.com, zhengtong@hit.edu.cn,664708558@qq.com, jjp_lab@sina.com) \\ b. State Key Laboratory of Urban Water Resource and Environment, Harbin Institute of Technology, \\ Harbin 150090, China; (pwang73@hit.edu.cn)
}

\begin{abstract}
Sudden river chemical spills accidents occurred frequently these years and caused great economic losses and odious social impacts. Although the current methods, such as the granular activated carbon package treatment in the Sudden Water Pollution Accident of Zhuozhang River of China, could make the water quality up to the standard, they resulted in the limited flow ability and low mass transfer capability, and also had some difficulty treating the unpredicted emergencies because of its location-specific treatment and time-consuming preparation work. Hence, a novel mobile industrial-scale fluidized adsorption process, which could address the above problems and was fast to deploy with simple operation, was developed in the paper for emergency water treatment. In the study, a lab-based Liquid-Solid Circulating Fluidized Bed (LSCFB) was prepared and the fluidized state was explored by validated computational fluid dynamics (CFD) models. The simulation results revealed that the particular uneven flow structure, which could weaken aniline removal performance, occurred with increasing superficial liquid velocity. Accordingly, an optimized distributor design was constructed by the established CFD models; notably, the effect of open angle on the fluidized state, which was often overlooked by previous studies, was mainly discussed. Then, the aniline removal rates of LSCFB pre and post optimization were compared. The experimental results demonstrated that dynamic adsorption capacity of the optimized LSCFB on aniline could reach approximately $70 \mathrm{mg} / \mathrm{g}$ under the optimum operating conditions (initial aniline concentration of $100 \mathrm{mg} / \mathrm{L}$, superficial liquid velocity of 3umf and sorbent dosage of $27 \mathrm{~g} / \mathrm{L}$ ). By comparison with fixed-bed adsorption, the LSCFB possessed significantly higher adsorption rate constants and shorter hydraulic retention time, which indicated that LSCFB could meet emergency treatment requirements in a better way. Finally, the study developed the mobile industrial-scale fluidized adsorption process and estimated process parameters for aniline removal in the Sudden Water Pollution Accident of Zhuozhang River.
\end{abstract}

Keywords: CFD simulation; Emergency treatment; Industrial-scale fluidized bed; Adsorption 